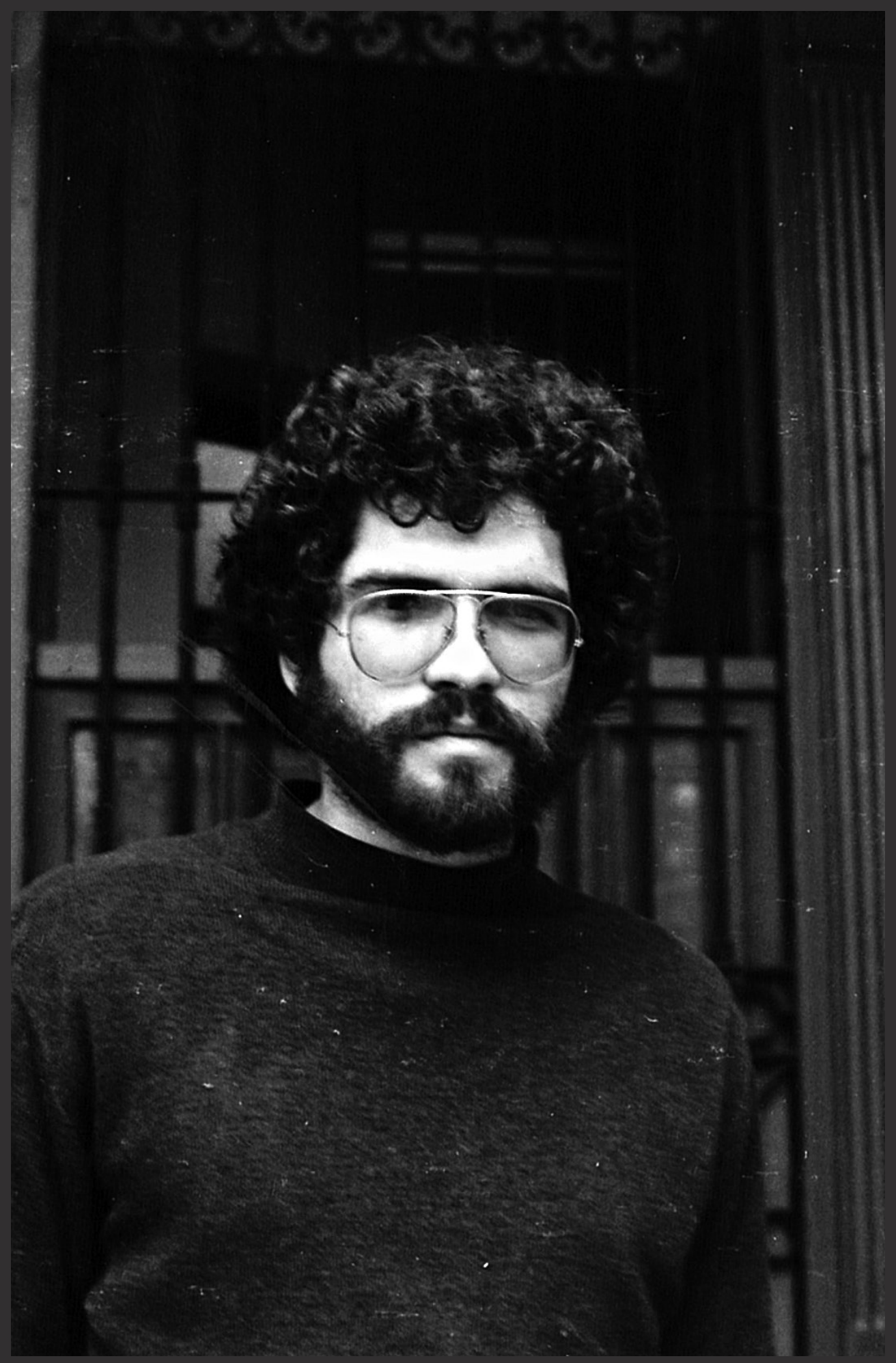

Juan Javier Salazar 1979.

Foto: Rolf Knippenberg. 


\section{Juan Javier Salazar}

(1955-2016)

Augusto del Valle Cárdenas

Director del Museo de Arte de San Marcos

Nos gustaba decir: "Juan Javier Salazar es, actualmente, nuestro mejor artista conceptual vivo”. Ahora ya no está más con nosotros. En este año, 2017, hemos sentido más que nunca su ausencia. El entrañable Juanja, como le decíamos sus amigos, nos dejó el primer día de noviembre del año pasado. Su conceptualismo, pienso, se forjó en la zona ciega de nuestro arte; esto es, en la década de 1970. Salazar había estudiado en la Sociedad Nacional de Bellas Artes de Lisboa, en 1972. Luego, con esa imagen residual del arte europeo en su retina, estudió hasta el cuarto año en la Ensabap. Esto coincide con 1976, año crucial para el surgimiento y la consolidación de un horizonte de arte contemporáneo en el Perú: aquel que define una articulación nueva y sorprendente entre el "arte moderno" y el llamado, en esa época, "arte popular". El retablista ayacuchano Joaquín López Antay había recibido un reconocimiento del Estado peruano, a manera de un Premio Nacional de "arte" y en la Ensabap los profesores de Juan Javier discutían si efectivamente el retablo era, por ejemplo, tan artístico como una pintura.

Desde 1979, su imagen en las páginas culturales aparece asociada al Grupo Paréntesis, un colectivo abierto por artistas, poetas, activistas y otros. Este había surgido en el verano de ese año con un aviso en los diarios en el que decían literalmente "Plásticos buscan mecenas". Asunto que sería el detonante para nuevos rumbos y búsquedas estéticas, diferentes a las tradicionales pintura y escultura. Desde el taller que, junto con otros, tenía Salazar, produce, por ejemplo, una pieza como Ace-Click, una suerte de ensamblage que luego de pasar por el aprendizaje de la técnica de la serigrafía, Mariotti y el Taller EPS Huayco, fructificaría, ya en la década de 1980, en una potente fusión, entre representación del agua a manera de onda expansiva y el juego con el nombre de la propia pieza.

Para la primera década del siglo XXI, la obra de Juan Javier Salazar, su conceptualismo, ya se había convertido en el referente de una generación de jóvenes artistas recién egresados de varias escuelas en Lima. Destaca, a mediados de la década de 1990, una acción en los ómnibus de transporte público de la ciudad de Lima, que consistía en "vender" un cojín que tiene la forma del perfil geográfico del Perú, adoptando de las maneras del vendedor popular. Asimismo, resulta clave de su última producción, un grupo de audiovisuales que configuran un lugar de la parodia y de la crítica de la cultura, todavía poco estudiados. En la fricción entre la imagen de estas piezas y sus narrativas, se hacía evidente, cada vez más, un desarrollo de los títulos de dichas piezas y juegos de elementos figurativos diversos; juegos con los que lograba sorprendentes articulaciones entre estereotipos visuales -provenientes tanto de las culturas precolombinas como de una vida cotidiana asociada a un ethos tan popular como hippie- y aquellos "mitos" a los que él mismo lograba darles vida con una oralidad potente $\mathrm{y}$, al mismo tiempo, sencilla pero generosa en términos existenciales. 